\title{
Carbon nanotubes reinforced conducting polyaniline and its derivative poly (o-anisidine) composites
}

\author{
S. B. Kondawar ${ }^{1, \star}$, S. W. Anwane ${ }^{2}$, D.V. Nandanwar ${ }^{3}$, S. R. Dhakate ${ }^{4}$ \\ ${ }^{1}$ Department of Physics, RTM Nagpur University, Nagpur, India \\ ${ }^{2}$ Centre for Nanotechnology, Shivaji Science College, Nagpur, India \\ ${ }^{3}$ Department of Physics, Mohata Science College, Nagpur, India \\ ${ }^{4}$ Carbon Unit, National Physical Laboratory, New Delhi, India
}

*Corresponding author: E-mail:sbkondawar@yahoo.co.in

\section{ABSTRACT}

Conducting polymer nanocomposites (PANI-CNT and POAS-CNT) have been synthesized by polymerization of aniline (ANI)/ $\mathrm{o}$-anisidine (OAS) in the presence of functionalized multiwall carbon nanotubes (MWCNTs). These nanocomposites have been characterized by UV-VIS, FTIR and SEM to study the effect of incorporation of MWCNTs on the morphology, structure and crystalline of the conducting polyaniline and its substitute derivate poly $\left(o\right.$-anisidine). UV-VIS spectra shows that polaron- $\pi^{*}$ and $\pi-\pi^{*}$ transition bands of the PANI/POAS chain shifted to longer wavelengths, indicating the interaction between quinoid rings and MWCNTs. FTIR spectra shows that the interaction between the MWCNTs and PANI/POAS may result in "charge transfer', whereby the $\mathrm{sp}^{2}$ carbons of the MWCNTs compete with dopant ions $\left[\mathrm{Cl}^{-}\right]$and perturb the H-bond, resulting an increase in the N-H stretching intensity. Electron microscopy reveals that the interaction between the quinoid ring of PANI/POAS and the MWCNTs causes PANI and POAS polymer chains to be adsorbed at the surface of MWCNTs, thus forming a tubular core surrounding the MWCNTs. The nanocomposites showed high electrical conductivity compared to pure PANI/POAS. Further, PANI-CNT showed high electrical conductivity compared to that of POAS-CNT. Copyright (C 2013 VBRI Press.

Keywords: Conducting polymers; polyaniline; poly(o-anisidine); multi-walled carbon nanotubes; nanocomposites.

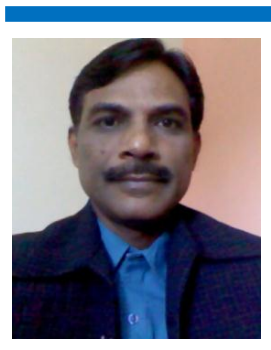

S. B. Kondawar is an Associate Professor of Physics at RashtrasantTukadojiMaharaj, Nagpur University, Nagpur, India. He did Ph.D. from Department of Physics, Institute of Science, Nagpur, India. His main research activities include the synthesis of advanced materials at nanoscale and use them to improve the properties of conducting polymer nanocomposites. His current research is focused on synthesis of conducting polymer nanotubes, nanofibers and nanocomposites for gas sensors, biosensors and solar cells. He has published more than 30 research articles in journals of international repute. He has completed two UGC, New Delhi (India) funded major research projects and one is ongoing to his credits.

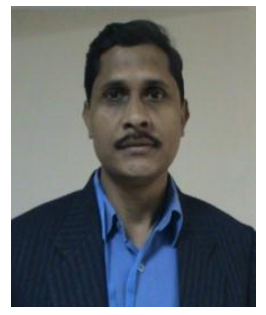

S. R. Dhakate is scientist working at National Physical Laboratory, New Delhi (India) from 1992. He did his Ph. D. from Dehli University. His research interests mainly on carbon materials i.e. Carbon fibers, Carbon Carbon composites, Carbon nanotubes, Graphene synthesis by exfoliation of graphite, Nanoribbons by unzipping CNTs, continuous polymer and carbon nanofibers by electrospinning, Development of carbon based PEM fuel cell components. He is a receipt of JSPS and JICA fellowship. He is receipt of Advanced Materials Letters Scientist award 2010 given International Association of Advanced Materials. Recently he got the JSPS Bridge Fellowship award (2011) to visit The University of Tokyo, Tokyo for 45 days.

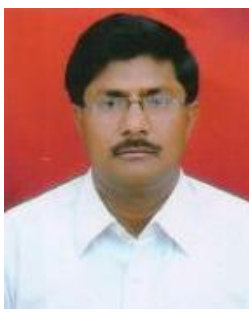

D. V. Nandanwar is an Associate Professor of Physics at Shri Mathuradas Mohata College of Science, Nagpur affiliated to Rashtrasant Tukadoji Maharaj Nagpur University, Nagpur (India). He did $\mathrm{Ph}$. D. from Department of Physics, Institute of Science, Nagpur. His main research activities include the synthesis of nanostructure conducting polymers for supercapacitors. He has published 5 research articles in national and international journals.

\section{Introduction}

In recent years two classes of organic materials like conducting polymers and carbon nanotubes have gained great interest for their unique physicochemical properties. Among the various conducting polymers, PANI (polyaniline) has received special recognition owing to its electrical conductivity, stability and its redox behaviour [1]. As the researchers studied its properties they realized that after adding nanomaterials as filler, the properties could be improved. Since the discovery by Ijima [2], carbon nanotubes (CNTs) have received much attention for their possible use in fabricating new classes of advanced material, due to their unique structural, optical, mechanical 
and electronic properties [3-5]. Introducing CNTs into a polymer matrix improves the properties of the original polymer [6]. PANI is one of the conducting polymers that have potential in the near term, due to its good processability, environmental stability and reversible control of conductivity both by charge-transfer doping and protonation [7]. The use of PANI together with CNTs to form nanocomposites could result in the formation of materials with extraordinary properties [8]. Though several studies have been done on PANI/CNTs nanocomposites, the electron conduction and stability of the nanocomposites still remain an issue [9]. The aim of this study is to fill the CNT in order to improve the interaction between the CNT and PANI or its substitute derivative POAS, which may lead to an increase in the electrical conductivity. Potential applications of these nanocomposites are in high energy portable electronics and supercapacitor properties [10].

\section{Experimental}

Monomers aniline and ortho-methoxyaniline (o-anisidine) purchased from Merck and used after purification. Oxidizing agent ammonium persulphate [( $\mathrm{NH} 4) 2 \mathrm{~S} 2 \mathrm{O} 8]$ and other reagents were obtained from Hi-media and used as received. High purity MWCNT with diameter between 30-40 nm was made available from NPL, New Delhi.

Polymer/CNT nanocomposites were synthesised by an in-situ polymerization of aniline using ammonium persulphate (APS) as oxidant in the presence of the functionalized CNT, as described in Zein et al. [11]. A solution of $\mathrm{HCl}$ containing a predetermined amount of CNT was sonicated at room temperature. Aniline monomer was dissolved in $\mathrm{HCl}$ solution and added to the CNT suspension and stirred. Ammonium persulphate (APS) was dissolved in $\mathrm{HCl}$ solution and then slowly added drop wise to the reaction mixture. After the suspension became green, indicating the formation of PANI/CNT in its emeraldine salt form, the nanocomposite obtained was filtered, washed several times with deionized water and dried for $24 \mathrm{~h}$. The same method was used for POAS/CNT nanocomposite. UV-vis spectra were performed on a Shimadzu UV-visible spectrophotometer. FTIR spectra were obtained on Perkin Elmer Fourier transform infra-red spectrophotometer. The morphology analysis of the nanocomposites was carried out using scanning electron microscope (SEM). The electrical conductivity was measured by using four point probe method.

\section{Results and discussion}

We studied the standardized oxidative polymerization, carried out for the synthesis of both pure conducting polymers and related nanocomposite materials, to investigate whether the presence of dispersed CNT into the medium of reaction could affect the polymer chains oxidation ratio in the final products of synthesis. For this purpose, we studied the UV-vis spectra to verify the amount of quinone-like structure per repeat unit. McCall and co-workers gave proof that the peak related to the $\pi$ $\pi *$ transition can give an estimation of the oxidation ratio comparing the related absorbance to that of $n-\pi^{*}$ one [12]. We thus took into consideration the peaks absorbance ratio, express as Abs $\left(\pi-\pi^{*}\right) / \operatorname{Abs}\left(\mathrm{n}-\pi^{*}\right)$, to calculate the reduced/oxidized ratio of the synthesized materials.

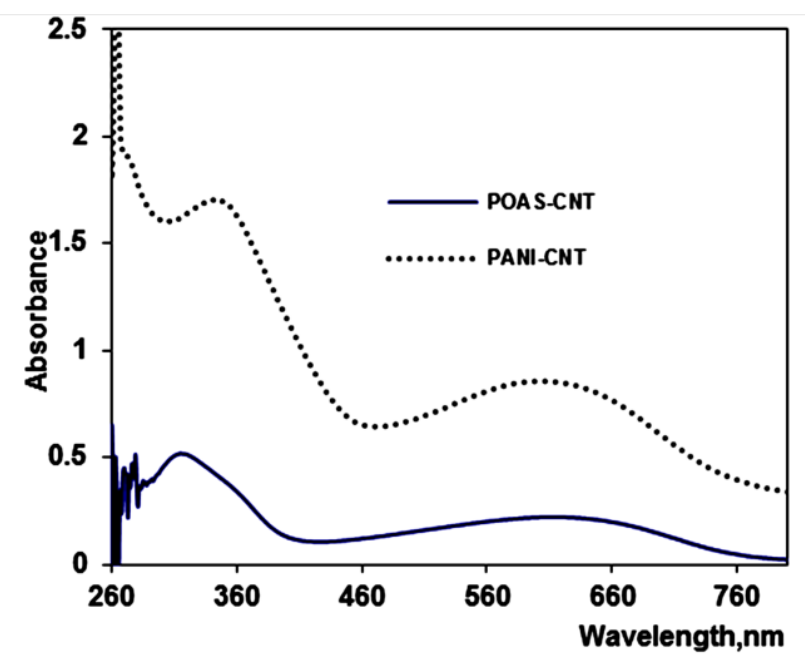

Fig. 1.UV-Vis spectra of PANI-CNT and POAS-CNT composites.

UV-Vis spectroscopy was utilised to understand the electronic states of PANI and POAS in PANI-CNT and POAS-CNT. The PANI showed two characteristic bands at $550 \mathrm{~nm}$ in visible corresponds to inter ring charge transfer ratio of benzenoid to quinoidmoities and at $290 \mathrm{~nm}$ in UV corresponds to $\pi-\pi^{*}$ transition along the backbone of the PANI chain [13], indicating that the resulting PANI emaraldine salt was in the doped state. As MWCNTs were incorporated with PANI (Fig. 1), the characteristic peaks of the PANI chain shifted to longer wavelengths, indicating the interaction between quinoid rings and MWCNTs [14]. The $\pi-\pi^{*}$ transition of PANI in the nanocomposites was also shifted to longer wavelengths. Similarly, the characteristics bands in POAS have also been shifted to longer wavelengths due to incorporation of MWCNTs indicating the interaction between quinoid rings and MWCNTs, observed in case of POAS-CNT [15].

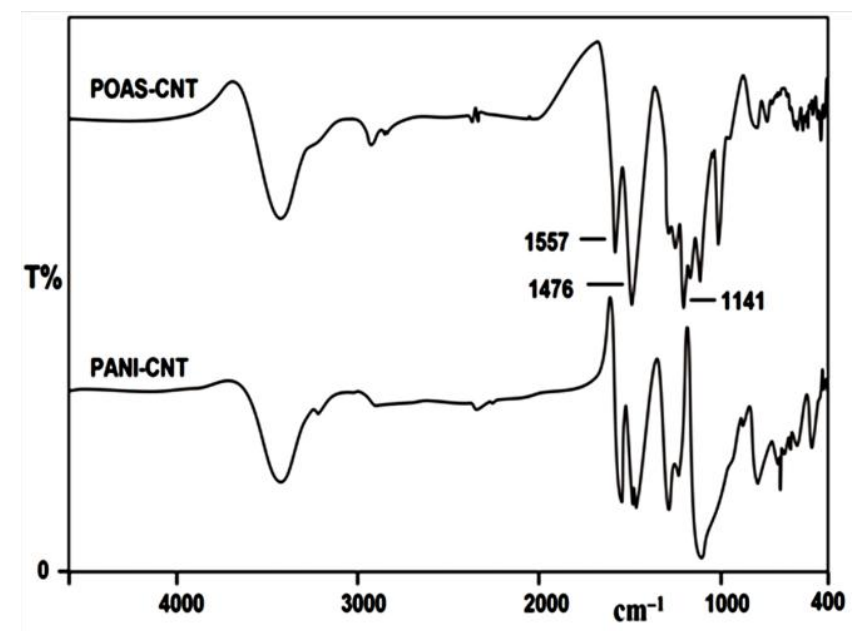

Fig. 2. FTIR spectra of PANI-CNT and POAS-CNT composites.

Fig. 2 shows the FTIR spectra of PANI-CNT and POAS-CNT. It exhibits the clear presence of benzoid at $1476 \mathrm{~cm}^{-1}$ and the quinoid ring vibration at $1557 \mathrm{~cm}^{-1}$, 
indicating the oxidation state of emaraldine salt of PANI [16]. The strong band around $1141 \mathrm{~cm}^{-1}$ is the characteristic peak of PANI conductivity and is a measure of the degree of the delocalization of electrons [13]. Very weak and broad band around $3000 \mathrm{~cm}^{-1}$ is assigned to the $\mathrm{N}-\mathrm{H}$ stretching mode. The N-H stretching region near $3000 \mathrm{~cm}^{-1}$ in figure 2 showed strong and broad peaks. The interaction between the MWCNTs and PANI/POAS may result in "charge transfer", whereby the $\mathrm{sp}^{2}$ carbons of the MWCNTs compete with dopant ions $\left[\mathrm{Cl}^{-}\right]$and perturb the $\mathrm{H}$-bond, resulting an increase in the $\mathrm{N}-\mathrm{H}$ stretching intensity [17]. Another difference is the intensity ratio of the benzoid and quinoid bands. In case of pure PANI the intensity of the quinoid band is less intense than benzoid band. The benzoid/quinoid intensity ratio for PANI-CNT and POASCNT is reduced considerably. This reveals that there are fewer benzenoid units in the nanocomposites compared to pure PANI. This may suggest that the MWCNTs promotes and stabilises the quinoid ring structure of the nanocomposites.
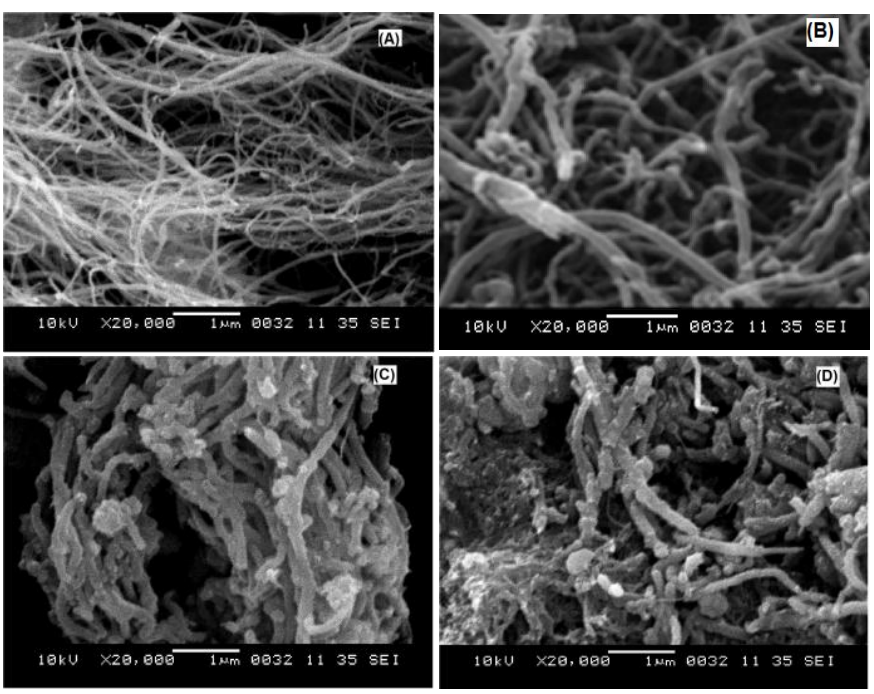

Fig. 3. SEM images of (a) CNT, (b)functionalized CNT, (c)PANI-CNT and (d) POAS-CNT.

SEM micrograph of CNT, functionalized CNT, PANICNT and POAS-CNT nanocomposites are shown in Fig. 3. Functionalized CNT shows weaker bonds as compared to that of pure CNT responsible for mixing with polymer. PANI-CNT and POAS-CNT nanocomposites show the homogeneous coating of PANI as well as POAS onto the CNT shown in Fig. 3, indicating that CNTs were well dispersed in polymer matrix. Composites show new interwoven fibrous structure with diameter about $115 \mathrm{~nm}$ which acts as conductive pathway and lead to high conductivity than that ofpure PANI.

To study the charge transport mechanism in the polymer composite, variation of conductivity with temperature of the nanocomposites were measured. From Fig. 4, the variation of conductivity with temperature indicates the "thermal activated behavior" for both the nanocomposites. The electrical conductivity of PANI-CNT and POAS-CNT was measured according to the standard four-point probe method. The room temperature conductivity of the composites was found to be $1.95 \mathrm{~S} / \mathrm{cm}$ and $0.16 \mathrm{~S} / \mathrm{cm}$ for PANI-CNT and POAS-CNT respectively. The enhancement in conductivity of PANICNT compared to neat PANI/POAS is due to the charge transfer effect from the quinoid rings of the PANI/POAS to the MWCNTs. Furthermore, the MWCNTs may serve as "conducting bridges", connecting the PANI/POAS conducting domains.

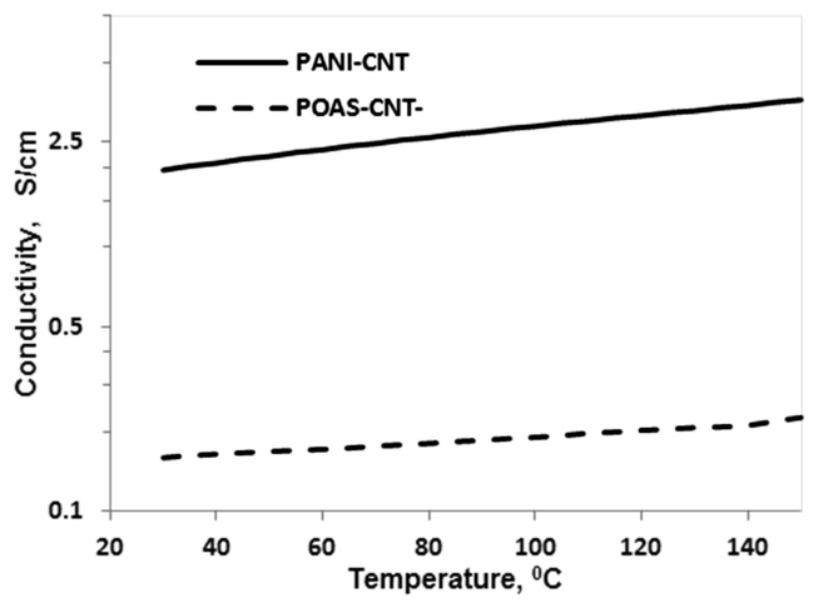

Fig. 4. Conductivity of PANI-CNT and POAS-CNT composites.

\section{Conclusion}

Nanocomposites of PANI-CNT and POAS-CNT were successfully prepared through the in-situ chemical oxidative polymerisation of aniline/o-anisidine. Nanocomposites showed good interaction, based on the shift in the electronic transition described by UV-VIS and FTIR spectra, which showed rich in quinoid rings. SEM revealed the filling of MWCNT and the uniform coating of PANI/POAS. The conductivity of PANI-CNT was higher than that of POASCNT.

\section{Acknowledgement}

The authors gratefully acknowledge UGC, New Delhi for financial assistance provided for this work through major research project F. No.39$540 / 2010$ (SR).

\section{Reference}

1. Pandi, G.; Ramaiah, S. Pure Appl. Chem. 2008, 80, 2377. DOI: $\underline{10.1351 / \mathrm{pac} 200880112377}$

2. Iijima, S. Nature. 1991, 354, 56. DOI: $10.1038 / 354056 \mathrm{a} 0$

3. De Heer, W.A.; Chatelain, A.; Ugarte, D. J. Phys. Sci.2009, 20, 27. DOI: $10.1126 /$ science.270.5239.1179

4. Odom, T.W.; Huang, J.L.; Kim, P.; Lieber, C.M. Nature1998, 391, 62. DOI: $1998 ; 391: 62-4$

5. Santos, C.V.; Hernandez, A.L.M.; Fisher, F.T. Chem. Mater.2003,15, 4470 . DOI: $2003 ; 15(23): 4470-5$

6. Zhong, H.; Yuan, R.; Chai, Y.; Li, W.; Zhong, X. Talanta.2011, 85, 104. DOI: $10.1016 /$ j.talanta.2011.03.040

7. Heeger, A.J. J. Phys. Chem. B.2001, 105(36), 8475. DOI: $10.1002 / 1521-3773(20010716) 40$

8. Konyushenko, E.N.; Stejskal, J.; Trchova, M.; Hradil, J.; Kovarova J.; Prokes, J.; Cieslar, M.; Hwang, J.Y.; Chen, K.H.; Sapurina, I. Polymer. 2006, 47(16), 5715.

DOI: $10.1016 /$ j.polymer.2006.05.059

9. Peng, C.; Jin, J.; Chen, G.Z. Electrochim. Acta. 2007, 53(2), 525. DOI: $10.1016 /$ j.electacta.2007.07.004 
10. Jiang, J.; Kucernak, A. Electrochim. Acta. 2002, 47(15), 2381. DOI: $10.1016 /$ S0013-4686(02)00031-2

11. Zein, S.H.S.; Yeoh, L.C.; Chai, S.P.; Mohamed, A.R.; Mahayuddin, M.E.M. J. Mat. Proc. Tech.2007, 190(1), 402. DOI:10.1016/j.jmatprotec.2007.03.104

12. McCall, R.P.; Ginder, J.M.; Leng, J.M.; Ye, H.J.; Manohar, S.K.; Masters, J.G. Phys Rev B, 1990, 41, 5202.

DOI: $10.1103 /$ PhysRevB.41.5202

13. Scherr, E.M.; MacDiarmid, A.G.; Monahar, S.K.; Masters, J.G.; Sun, Y.; Tang, X. Synth. Met.1991, 41(1), 735. DOI: 10.1016/0379-6779(91)91173-8

14. Xia, H.; Wang, Q. J. Appl. Polym. Sci., 2003, 87(11), 1811. DOI: $10.1002 /$ app.11627

15. Bavastrello, V.; Terencio, T.B.C.; Nicolini, C.; Polymer 2011, 52(1), 46.

DOI:10.1016/j.polymer.2010.10.022

16. Quillard, S.; Louarn, G.; Lefrant, S.; MacDiarmid, A.G. Phy. Rev. B, 1994, 50(17), 12496.

DOI: $10.1103 /$ PhysRevB.50.12496

17. Cochet, M.; Maser, W.K.; Benito, A.M.; Callejas, M.A.; Martinez, M.T.; Benoit, J.M.; Schreiber, J.; Chauvet, O. Chem. Commun.2001, 16,1450 .

DOI: $10.1039 / B 104009 \mathrm{~J}$

\section{Advanced Materials Letters}

\section{Publish your article in this journal}

ADVANCED MATERIALS Letters is an international journal published quarterly. The journal is intended to provide top-quality peer-reviewed research papers in the fascinating field of materials science particularly in the area of structure, synthesis and processing, characterization, advanced-state properties, and applications of materials. All articles are indexed on various databases including DOAJ and are available for download for free. The manuscript management system is completely electronic and has fast and fair peer-review process. The journal includes review articles, research articles, notes, letter to editor and short communications. 